\title{
Compreensão fenomenológica de enfermeiros intensivistas à luz do pensamento humanístico de Paterson e Zderad
}

\author{
Phenomenological understanding of intensivist nurses in light of the humanistic thought of \\ Paterson and Zderad
Comprensión fenomenológica de enfermeros intensivistas a la luz del pensamiento humanístico de Paterson y Zderad

\author{
Loraine Machado de AraújoI L Lorena Machado de Araújo ${ }^{I I}$
}

\begin{abstract}
RESUMO: O estudo objetivou compreender a percepção de enfermeiros acerca do processo de cuidar de pacientes internados em unidade de terapia intensiva. Trata-se de uma pesquisa descritiva qualitativa, de abordagem fenomenológica, fundamentada na Teoria Humanística de Paterson e Zderad, realizada no hospital universitário, em Natal, Rio Grande do Norte, no período de janeiro/fevereiro de 2009. O grupo pesquisado consta de sete enfermeiros, tendo a entrevista semiestruturada como instrumento de coleta de dados e a análise delineada segundo Bardin. Na análise, evidenciaram-se as seguintes categorias: O tempo e o espaço no cotidiano da enfermagem; $O$ encontro existencial entre enfermeiro e paciente; $O$ cuidado dialógico na relação terapêutica; A transação intersubjetiva diante do sofrimento; e O vir-a-ser na relação profissional/família. Este estudo revelou que a enfermagem mantém como foco o cuidar e considera as relações intersubjetivas como elo entre enfermeiro/ paciente/família nesse contexto.

Palavras-Chave: Enfermagem; unidade de terapia Intensiva; humanização da assistência; teoria de enfermagem.
\end{abstract}

ABSTRACT: This qualitative, descriptive study to understand nurses' perceptions of the process of caring for patients in an intensive care unit was conducted at the university hospital in Natal, Rio Grande do Norte, from January to February 2009. The phenomenological approach was based on the Humanistic Theory of Paterson and Zderad. The study group comprised seven nurses, from whom data was collected by semi-structured interview. Data analysis, following Bardin, revealed the categories: time and space in day-to-day nursing; the existential encounter between nurse and patient; dialogical care in the therapeutic relationship; intersubjective transaction regarding suffering; and coming-to-be in the relationship between professional and family. The study revealed that nursing remains care-focused and considers inter-subjective relations as linking nurse, patient and family in this context.

Keywords: Nursing; intensive care unit; humanization of care; nursing theory.

RESUMEN: El estudio tuvo como objetivo comprender la percepción de enfermeros sobre el proceso de cuidar a los pacientes internados en una unidad de cuidados intensivos. Se trata de una investigación descriptiva cualitativa, con abordaje fenomenológico, basada en la Teoría Humanística de Paterson y Zderad, realizada en el hospital universitario de Natal, Rio Grande do Norte, entre enero / febrero de 2009. El grupo investigado era compuesto por siete enfermeros; la entrevista semiestructurada ha constituido la herramienta de recolección de datos y el análisis fue delineado según Bardin. En el análisis surgieron las categorías: el tiempo y el espacio en el cotidiano de la enfermería; el encuentro existencial entre enfermero y paciente; el cuidado dialógico en la relación terapéutica; la transacción intersubjetiva ante el sufrimiento; y el venir-a-ser en la relación profesional / familia. Este estudio reveló que la enfermería mantiene el foco en el cuidado y considera las relaciones intersubjetivas como un eslabón entre enfermero / paciente / familia en este contexto.

Palabras Clave: Enfermería; unidad de cuidados intensivos; humanización de la asistencia, teoría de enfermería.

\section{INTRODUÇÃO}

O cuidado é parte integrante da vida humana e envolve, numa dimensão existencial do ser, uma atitude entre seres humanos relacionados ao sentimento e à valorização da experiência de vida. O cuidado ocorre nessa intersubjetividade humana em um encontro genuíno entre profissional e ser cuidado, em um movimento de complementaridade de sentimentos, ações e reações ${ }^{1}$.
$\mathrm{Na}$ unidade de terapia intensiva (UTI), a assistência de enfermagem é estabelecida de uma forma diferente em função de sua especificidade. Nessa perspectiva, as máquinas de suporte de vida como ventiladores mecânicos, balões intra-aórticos e monitores cardíacos são tecnologias que exigem da enfermagem competências para o cuidar ${ }^{2}$. Nesse setor, marcado pelo

IEnfermeira Especialista em Enfermagem do Trabalho. Departamento de Enfermagem, Universidade Federal do Rio Grande do Norte. Natal, Rio Grande do Norte, Brasil. E-mail: Loraine-machado@hotmail.com.

"Enfermeira, Mestranda do Programa de Pós-Graduação em Saúde Coletiva da Universidade Federal do Rio Grande do Norte. Especialista em Enfermagem do Trabalho. Natal, Rio Grande do Norte, Brasil.E-mail: lorena_araujo_@hotmail.com. 
avanço tecnológico, o cuidar parece está relacionado a tais máquinas, tornando a assistência, em determinadas ocasiões, contraditórias ${ }^{1,3}$.

Assim, diante dessa realidade, fica evidente que para efetivar a compreensão do paciente na prática cotidiana do cuidar em UTI são necessárias a escuta, a presença e a sensibilidade para ativar a verdadeira dimensão existencial de cada partícipe dessa relação. Dessa forma, valores humanísticos precisam estar presentes no processo de cuidar, possibilitando tornar holísticas as ações vivenciadas no cotidiano da enfermagem $^{1}$. Sabendo que a arte da enfermagem é a capacidade do indivíduo perceber a expressão de sentimentos de outros e experimentá-los com seus próprios, é necessária a proximidade com a experiência subjetiva do paciente, fornecendo uma base para essa relação ${ }^{4}$.

A partir da necessidade de reflexões mais aprofundadas, buscou-se a Teoria Humanística de Paterson e Zderad, na qual a partir de seus pressupostos permite a aproximação entre os enfermeiros e pacientes como experiência existencial, evidenciadas pela expressividade e potencialidade ${ }^{3}$.

Nesse sentido, a intersubjetividade supera o tecnológico a partir da compreensão da realidade por meio da experiência vivida, da reflexão e do relacionamento, permitindo a abertura para que os seres humanos experienciem o mundo e a si próprios de forma integral ${ }^{1}$. Doravante, traçou-se como objetivo para este estudo: refletir sobre o cuidado humanizado prestado pelo enfermeiro junto ao paciente internado em UTI, orientado pela Teoria Humanística de Paterson e Zderad.

\section{Referencial TeÓRICo}

A Teoria Humanística de Paterson e Zderad parte do pressuposto que a ciência da enfermagem se desenvolve a partir das experiências vividas entre enfermeiros e pacientes, constituindo o significado dessa experiência o ponto de partida para o estabelecimento de uma relação intersubjetiva. De acordo com a teoria, os cuidados prestados pela enfermagem seguem em busca do alcance do bem-estar e do ser mais, estabelecendo necessariamente um encontro entre pessoas humanas únicas (eu e tu), orientado por um chamado (necessidade) e uma resposta intencional (o cuidado) ${ }^{5}$.

Nesse contexto, a enfermagem tem na fenomenologia uma importante contribuição para o seu pensar e o seu fazer. A enfermeira deve estar preparada para vir-a-conhecer, sendo o autoconhecimento necessário, bem como estar receptiva para o desconhecido, disposta a ser surpreendida e a conhecer a vivência dos pacientes a partir da transcendência de si mesmo, recordando, refletindo e experimentando a relação eu-tu ${ }^{6}$.

As ações de enfermagem caracterizam-se por um diálogo vivo, envolvido pelo encontrar-se, relacionar- se e estar presente. É a partir dele que a enfermagem vai conciliar a razão, a sensibilidade e a subjetividade no ato de cuidar ${ }^{5}$.

De acordo com a Teoria Humanística de Paterson e Zderad, o ser humano não existe de modo abstrato, descontextualizado social e historicamente, ele está em constante relação com o outro em uma atitude genuína. Isto significa que se o sujeito for valorizado em sua singularidade e subjetividade, será reconhecido como ser existencial ${ }^{7}$. Nesse sentido, entende-se que o cuidado não pode ocorrer isoladamente, pois é um processo interativo entre aquele que cuida e aquele que é cuidado e se desenvolve por meio da disponibilidade, confiança e aceitação ${ }^{8}$.

Baseado na Teoria Humanística de Paterson e Zderad, o cuidado implica estar aberto ao outro, disponível e desprovido de qualquer julgamento de modo recíproco e ser capaz de identificar, de modo verbal ou não verbal, as necessidades emergentes do outro, atendendo-as adequadamente? .

Assim, considerar a vinculação entre o eu e o outro é uma relação de observador e observado, na qual a fenomenologia trouxe à tona a experiência subjetiva, como uma parte essencial da interação sistêmica do organismo com o meio ambiente, levando a formas de cuidados e modos de experiência, inclusive empreendimentos ou reações de si e do mundo ${ }^{10}$.

\section{Metodologia}

Trata-se de um estudo qualitativo, do tipo descritivo, de natureza fenomenológica à luz do referencial Teórico Humanístico de Paterson e Zderad³ . O lócus da pesquisa foi um hospital universitário, em Natal/ RN, no setor de UTI, no período de janeiro a fevereiro de 2009. Conforme as diretrizes e critérios éticos da Resolução no 196/96, do Conselho Nacional de Saúde, o seguimento da pesquisa ocorreu após a autorização da instituição, bem como a aprovação pelo Comitê de Ética em Pesquisa da Universidade Federal do Rio Grande do Norte, mediante o Parecer n 079/2009.

Participaram do estudo sete enfermeiros, escolhidos por conveniência, incluindo todos os que trabalhavam na UTI, até obter a saturação teórica. Foi definido como critério de inclusão trabalhar no setor há pelo menos dois anos, e de exclusão, os que não se enquadrassem no critério anterior. Os enfermeiros participaram voluntariamente da pesquisa mediante o esclarecimento detalhado acerca dos propósitos do estudo, assim como a assinatura do Termo de Consentimento Livre e Esclarecido (TCLE).

Utilizou-se como instrumento de coleta de dados uma entrevista semiestruturada, segundo a abordagem fenomenológica, conforme a questão norteadora: No tocante à humanização, fale sobre sua experiência na assistência em UTI. A fim de complementar o entendi- 
mento da questão, foram feitas, também, perguntas sobre vivências anteriores sobre a humanização.

Os depoimentos foram gravados após a autorização dos entrevistados, mediante a garantia do sigilo e anonimato, e, posteriormente, transcritos e analisados. Para identificação dos participantes na pesquisa, utilizou-se a numeração de 1 a 7 , de acordo com a ordem das entrevistas, antecedida pela letra E, correspondente à função de enfermeiro.

Para a compreensão dos discursos, utilizou-se a técnica de análise de conteúdo, na modalidade de análise temática, segundo Bardin ${ }^{11}$. Essa fase foi realizada em três momentos: pré-análise (leitura flutuante dos dados transcritos); exploração do material (seleção das falas dos sujeitos e organização das categorias) e tratamento dos resultados (interpretação).

A escolha da abordagem filosófica/fenomenológica com base na Teoria Humanística de Paterson e Zderad, deu-se pelo fato desta apresentar uma metodologia congruente com a dimensão analítica existencial ${ }^{3}$. A fenomenologia busca uma melhor investigação e compreensão da essência da experiência vivida e de como o indivíduo percebe o fenômeno na sua prática existencial, conferindo, portanto, uma interpretação mais fidedigna das percepções cotidianas.

\section{Resultados e Discussão}

Os depoimentos evidenciaram situações e particularidades que culminaram na construção de cinco categorias intituladas como: $O$ tempo e o espaço no cotidiano da enfermagem; $\mathrm{O}$ encontro existencial entre enfermeiro e paciente; $\mathrm{O}$ cuidado dialógico na relação terapêutica; A transação intersubjetiva diante do sofrimento; e $\mathrm{O}$ vir-a-ser na relação profissional/ família.

\section{O tempo e o espaço no cotidiano da enfer- magem}

A UTI tem incorporado à assistência um aparato tecnológico cada vez mais sofisticado, mas para garantir um cuidado de qualidade é necessário agregar também a integralidade da assistência ${ }^{12}$. De acordo com os depoimentos, os enfermeiros consideram a unidade de terapia intensiva um ambiente favorável para o desenvolvimento das ações do cuidado e a equipe colabora positivamente para a efetivação do trabalho humanizado.

Acho o setor organizado, onde você tem condições de atender o paciente na hora que ele precisa [...]. A equipe também é muito organizada e gosta de cuidar. (E3)

A UTI é um local onde o enfermeiro consegue, de fato, atuar, pois o número de pacientes é menor, então, o enfermeiro consegue ficar mais próximo e ter um conhecimento maior sobre sua evolução. (E1)
Entretanto, o processo de internação interfere diretamente na rotina e autonomia do paciente, além de provocar o distanciamento da família e amigos, vivenciado por uma separação de estar-nomundo, desvelando sensações de medo em relação à doença e ao tratamento ${ }^{13}$. A internação, dessa forma, caracteriza-se como uma situação de estresse, não só devido à dinâmica da unidade, mas, também, por guardar correlação, no imaginário das pessoas, com sofrimento e morte ${ }^{5}$.

As pessoas falam que a UTI é um local de morte; às vezes, os pacientes chegam com medo. Mas não é bem assim, aqui é um local de vida. Só vêm aqueles viáveis para sobreviver. (E7)

Assim, numa dimensão ética, toda ação implica valores, compromisso e responsabilidade. Em relação aos pacientes internados em UTI, o cuidado associase à sua vulnerabilidade, por estar dependente do cuidado e do comprometimento moral de quem os cuida num modo-de-ser no mundo ${ }^{14}$.

\section{O encontro existencial entre enfermeiro e paciente}

Os enfermeiros entendem que o cuidar é algo mais do que a assistência, ele não se restringe às técnicas e aos cuidados rotineiros, mas exige uma visão que ultrapasse o biológico, enfatizando o sentido de ser do paciente e a preocupação com todos os aspectos do cuidar ${ }^{15}$.

Quando vou colher sangue sempre aviso porque a audição é a última coisa que eles perdem. Eu sempre tento considerar o aspecto psicológico. (E1)

Transportando o conceito de vir-a-ser mais e melhor para a UTI, o enfermeiro atua como um apoio para que o paciente se sinta cada vez mais acolhido. Isso ocorre ao relacionar-se simultaneamente com os aspectos subjetivos e objetivos da situação vivida, respeitando suas condições físicas e emocionais ${ }^{5}$. Isso pode ser comprovado no depoimento a seguir:

Se ele está com um olhar espantado, eu tento estimular para ver se ele me informa se está com dor para ser medicado. (E4)

Muitas vezes, o paciente de UTI está afastado de qualquer tomada de decisão quanto à sua vida, à sua doença e ao seu corpo, sendo umas das principais causas da ansiedade a falta da família e o isolamento social. A enfermagem, que ajuda a maximizar a possibilidade e a capacidade dos pacientes fazerem escolhas, busca oferecer uma resposta de cuidado ${ }^{5}$. Assim, é necessário um plano individualizado a fim de melhorar o seu bem-estar ${ }^{13}$. Exemplo desse plano pode ser encontrado na fala:

Às vezes, quando o paciente não aceita a comida e a família chega para visitar, eles tentam dar a alimentação. (E4) 
Segundo a Teoria Humanística de Paterson e Zderad, o encontro autêntico do enfermeiro com o paciente pode resultar, então, em conforto, na medida em que há envolvimento com o outro em relações verdadeiras. Isso implica a pessoa sentir-se cuidada, estimada, segura e protegida, de forma a poder vivenciar um sentimento de harmonia consigo mesma e com o ambiente ${ }^{5}$. No depoimento, o enfermeiro expressa a forma como ele procura atender ao paciente:

Eu conforto o paciente tentando minimizar as angústias e ansiedade, [...] mostrando que eu não estou ali só para furar. (E5)

Isto significa conhecer e compreender o processamento de reações ou respostas emocionais decorrentes do significado atribuído à doença e implementar estratégias de enfrentamento para tal. E esse encontro envolve uma rede de conexões inseparáveis que, contextualizadas dentro de uma realidade, confere sentido à experiência de cuidar ${ }^{16}$.

\section{O cuidado dialógico na relação terapêutica}

Sabe-se que a comunicação - que ocorre na forma de chamados verbais e não verbais - pode influenciar positivamente as ações de enfermagem. $\mathrm{O}$ enfermeiro deve estar aberto ao todo da experiência e ser capaz de perceber esses chamados, intervir e dialogar, promovendo uma relação intersubjetiva entre quem cuida e quem é cuidado ${ }^{5}$. Apesar de existirem algumas dificuldades, os enfermeiros tentam superá-las.

O paciente consciente diz o que está sentindo, os inconscientes você observa no olhar, mesmo sem palavras. (E3)

Nesse encontro existencial, é importante que o enfermeiro busque conhecer o outro numa atitude de ser-com-o-outro para que a relação aconteça de forma positiva e estabeleça a confiança ${ }^{5}$. Ao considerar a perspectiva de mundo do paciente, o enfermeiro poderá suprir suas reais necessidades e minimizar os traumas da internação e dos tratamentos ${ }^{15}$. Portanto, numa perspectiva terapêutica, o relacionamento enfermeira/ paciente pauta-se na experiência prévia dos sujeitos ${ }^{17}$.

Sempre procuramos escutar a estória do paciente; porém, muitas vezes, eles estão entubados e não conseguem falar. Então o enfermeiro tenta se aproximar e interagir. (E7)

O enfermeiro deve ver realmente o que o paciente precisa. É necessário fazer exames todos os dias? Causar um sofrimento para o paciente sem prognóstico. (E2)

Frente a essas considerações, observa-se que o cuidado de enfermagem implica habilidade do profissional em ajudar as pessoas a superarem seus problemas, em se relacionar com os demais e enfrentar o que não pode ser mudado ${ }^{17,18}$. Assim, toda ação exige a presença da sensibilidade e o espírito de doação, conforme mostra a fala do enfermeiro.
Você sempre tem algo a fazer por um paciente de UTI, e isso me faz aproximar dele. (E3)

\section{A transação intersubjetiva diante do sofrimento}

Uma aproximação mais estreita dos enfermeiros com os pacientes está relacionada ao longo tempo de internação na unidade, o que, muitas vezes, propicia àqueles a projeção do sofrimento dos pacientes para $\mathrm{si}^{19}$. Portanto, como uma estratégia para o não envolvimento emocional e para melhor lidar com a ansiedade numa atitude eu-isso, os profissionais tendem a manter um afastamento. A partir disso, faz-se necessário que o profissional saiba diferenciar os limites do envolvimento terapêutico, como pode ser evidenciado nos depoimentos dos enfermeiros.

Foi um desafio aprender a cuidar de pacientes com uma complexidade maior [...] lidar com a morte e a ansiedade da família. (E4)

O ambiente de UTI é insalubre, às vezes estou uma pilha, só escutando falar de morte e sofrimento [...]. Não tem como deixar de absorver, precisamos de um apoio. (E6)

Nesses depoimentos, observa-se a necessidade de um suporte a fim de estabelecer um equilíbrio emocional do profissional para o desempenho eficaz de suas funções, voltado para o bem-estar e o estarmelhor do paciente.

Tem situações que nos choca demais, a gente chora [...] me sinto muito mal. (E1)

A gente lida com a morte na UTI, mas não é que estejamos adaptados. Tentamos conviver melhor com isso, agindo de uma forma mais amena até pra não trazer mais sofrimento para o familiar que já está desesperado. (E6)

\section{O vir-a-ser na relação profissional/família}

Pode-se considerar que no ambiente físico e social da UTI se concentram estímulos que podem ser fonte de estresse para os familiares, os quais vivenciam insegurança, ansiedade, desconforto e depressão ${ }^{5}$. Nesse sentido, a atitude dos profissionais não deve apenas se concentrar nos pacientes, mas também nos familiares.

A família é importante, mas humanização não é só deixar a família ficar com o paciente na UTI 24 horas por dia. (E7)

A visita aproxima o paciente da família, mas, algumas só vêm trazer problemas. Nesse caso, o enfermeiro precisa intervir; humanizar, às vezes, é tirar a família. (E2)

Se faz mister considerar também o desenvolvimento de um modelo assistencial em que o relacionamento enfermeiro/família numa atitude eu-tu se configure como espaço ativo e crítico, enfatizando uma abordagem humanizada ${ }^{17}$. A aproximação a essas vivências dos familiares de pacientes, envolvendo o 
acolhimento, consiste justamente em reconhecer a sua subjetividade e a sua importância no acompanhamento do paciente, incorporando-a como foco importante do cuidar ${ }^{20}$. Essa relação destaca-se no depoimento a seguir:

A gente estabelece vínculo tanto com o paciente [...] quanto da família [...]; no horário de visita eles ficam nos procurando... não tem como deixar de se envolver. (E5)

O enfermeiro deverá, portanto, assumir-se como pilar central da família, dando orientações claras, precisas e estabelecendo uma efetiva relação de ajuda. Um ponto essencial para qualificar esse atendimento consiste justamente em reconhecer a subjetividade e a importância daqueles no acompanhamento do paciente $^{21}$. Assim, a assistência de enfermagem envolve relações com a família e o meio social do paciente, pois é conhecendo-o que ela poderá vê-lo de modo holístico e dar-lhe uma assistência integrada ${ }^{15}$.

\section{Conclusão}

As teorias de enfermagem são consideradas aportes epistemológicos fundamentais à construção do saber e da prática profissional, pois direcionam o modelo clínico da enfermagem e possibilitam aos profissionais descreverem os aspectos da realidade assistencial, auxiliando o desenvolvimento da tríade teoria, pesquisa e prática. Dessa forma, acredita-se que o uso das teorias de enfermagem apoia-se na definição do papel da enfermagem, na qualidade do desempenho profissional e na produção do conhecimento.

A Teoria Humanística de Paterson e Zderad, baseada numa dimensão fenomenológica, revela a necessidade de resgatar a dimensão humana do cuidado, contraponto ao modelo biomédico que ainda impera, atualmente, na área da saúde e que, de certa forma, restringe o modo de vivenciar o processo saúde-doença.

De acordo com o estudo, percebe-se que a enfermagem mantém a essência da profissão, que é o cuidar com a preocupação com o outro e o faz por meio da comunicação terapêutica efetiva. Assim, entende-se que isso corresponde à autenticidade do existir humano. Foi possível apreender, nas falas, que os profissionais de enfermagem, apesar das características inerentes ao complexo ambiente hospitalar, estabelecem relações interpessoais e consideram a presença de sentimentos humanos nas ações de cuidar tão importantes quanto as atividades técnicas.

Dessa forma, numa dimensão humanística, apesar da constante vivência com a dor e o sofrimento do outro, os profissionais mostram-se comprometidos com o cuidar, incluindo neste a família, na qual compreendem a importância de suas ações e definem claramente os seus limites de atuação profissional como seres humanos.
Como limitação do estudo, pode-se citar a necessidade de mais pesquisas a fim de compreender melhor as dificuldades que os enfermeiros enfrentam no dia a dia de trabalho e buscar desenvolver estratégias que minimizem os estresses diários e ampliem o cuidado humanizado.

\section{REFERÊNCIAS}

1.Cunha PJ, Zagonel IPS. As relações interpessoais nas ações de cuidar em ambiente tecnológico hospitalar. Acta Paul Enferm. 2008; 21: 412-9.

2.Silva RCL, Porto IS, Figueiredo NMA. Reflexões acerca da assistência de enfermagem e o discurso de humanização em terapia intensiva. Esc Anna Nery. 2008; 12: 156-9.

3.Paterson JE, Zderad LT. Enfermería humanística. Cuidad de México (MEX): Editorial Limusa S.A.; 1979. 4.Acuña MR, Burgos MA. Fenomenología y conocimiento disciplinar de enfermería. Rev Cubana Enfermer [online]. 2013; 29:191-8.

5.Mercês CAMF, Rocha RM. Teoria de Paterson E Zderad: um cuidado de enfermagem ao cliente crítico sustentado no diálogo vivido. Rev enferm UERJ. 2006; 14: 470-5.

6.Aguiar MIF, Braga VAB. O significado do transplante de fígado para o paciente em lista de espera: abordagem fenomenológica. Rev Cubana Enfermer [online]. 2012; 28: 485-94.

7.Schneider DG, Manschein MM, Ausen MAB, Martins JJ, Albuquerque GL. Acolhimento ao paciente e família na unidade coronariana. Texto contexto - enferm. 2008; 17:81-9. 8.Grudtnen DI, Carraro TE, Sobrinho SH, Carvalho ALG, Campregher G. O amor no cuidado de enfermagem. Rev enferm UERJ. 2010; 18: 317-22.

9.Josephine EP, Loretta TZ. In: George JB. Teorias de enfermagem: os fundamentos para a prática profissional. Porto Alegre (RS): Artes Médicas; 1993. p. 242-53.

10.Ávila C, Emilce F. Intersubjetividad: entre explicación y comprensión. Rev colomb psiquiatr. [online] 2014; 43: $52-7$.

11.Minayo MCS. O desafio do conhecimento: pesquisa qualitativa em saúde. 8ª ed. São Paulo (SP): Hucitec; 2004. 12.Bolela F. A humanização em terapia intensiva na perspectiva da equipe de saúde [dissertação de mestrado]. Ribeirão Preto (SP): Universidade de São Paulo; 2008. 13.Furuya RK, Birolim MM, Biazin DT, Rossi LA. A integralidade e suas interfaces no cuidado ao idoso em uma unidade de terapia intensiva. Rev enferm UERJ. 2011; 19: 158-62.

14.Oguisso T, Schmidt MJ, Freitas JF. Ética e a bioética na enfermagem. In: Oguisso T, Schmidt MJ. O exercício da enfermagem: uma abordagem ético-legal. Rio de Janeiro: Guanabara Koogan; 2007. p.71-80.

15.Ferreira NMLA, Valle ERM. Ser-com-o-outro no mundo do cuidado. Rev enferm UERJ. 2005; 13: 354-60. 16. Magdalena AC. The need for a phenomenological perspective on caring in the nursing curriculum. Invest educ enferm. [online] 2013; 31: 142-5. 
17.Veiga KCG, Fernandes JD, Sadigursky D. Relacionamento enfermeira/paciente: perspectiva terapêutica do cuidado. Rev enferm UERJ. 2010; 18: 322-5.

18.Barros SDOL, Queiroz JC, Melo RM. Cuidando e humanizando: entraves que dificultam esta prática. Rev enferm UERJ. 2010; 18: 598-603.

19.Martins JT, Robazzi MLCC. O trabalho do enfermeiro em unidade de terapia intensiva: sentimentos de sofrimento. Rev Latino- Am Enfermagem. 2009; 17: $52-8$.

20. Ramiro D, José H. Humanização da saúde: da intenção à inteligência emotiva pelas idéias. Ideas y valores. 2012; 61 (148): 23-35.

21.Carolina MGH, Helena CBPC. Cuidar em enfermagem: estudo fenomenológico. Indagatio Didactica. 2013; 5:1003-15. 